\title{
Clinical profile of severe acute malnutrition in western rajasthan: a prospective observational study from india
}

\begin{abstract}
Introduction: The present study is undertaken to evaluate incidence and clinical profile of patients admitted with severe acute malnutrition and the assessment of relative contribution of various variables.

Methods and material: This prospective study was conducted at department of paediatrics Umaid hospital, Dr. S.N. medical college Jodhpur, for a period of 7 months on patients of severe acute malnutrition admitted in malnutrition treatment corner. A total of 75 cases were enrolled in the study and a detailed history and physical examination finding were recorded in pretested proforma at the time of admission by using standard methodology and anthropometric measurement expressed in standard deviation from the median of the reference population (NCHS).
\end{abstract}

Results: Incidence of severe acute malnutrition is 3.28\%. Mean age of admitted patients was $14.92 \pm 7.48$ months and mostly belonged to lower socioeconomic scale, rural area and large family. Most of the caretakers were illiterate and in all cases, caretakers were mothers. In our study that $41.3 \%, 32.1 \%, 21.3 \%$ and $5.3 \%$ patients were in PEM grade IV, III, II and I respectively. Female patients were more severely malnourished than males $(84.2 \% \mathrm{v} / \mathrm{s}$ $68.21 \%$ ).Most common presenting symptom was fever (70.7\%), followed by vomiting (52) and co morbidity associated with PEM was gastrointestinal $(60 \%)$ followed by respiratory tract infection (52\%). Mean duration of exclusive breast feeding was $2.6 \pm 1.5$ months and mean age of weaning was $8.4 \pm 3.9$ months. $78.7 \%$ children were still on breast feed at the time of hospitalisation and among them $40.7 \%$ of children were above 12 months of age. Mean age of starting semisolid and solid food was $11.6+3.53$ months and most commonly used supplementary food was top milk in (100\%), followed by chapati $(42.3 \%)$ in patients.

Conclusion: On the basis of this study, we conclude that the problem of severe malnutrition is multi-dimensional and inter-generational in nature. The determinants of severe malnutrition includes household food insecurity, illiteracy, low socioeconomic status, lack of awareness to access health services, large family size and poor purchasing power etc. Besides these, faulty feeding practices, poor complementary feeding practices, ignorance about nutritional needs of infants and young children and repeated infections, also aggravates the malnutrition amongst children.

Keywords: clinical profile, severe acute malnutrition
Special Issue - 2015

\author{
Rajendra Prasad Nagar,' Mukesh \\ Choudhary, ${ }^{2}$ Deepak Sharma,3 Brahma Dutt \\ Gupta, ${ }^{4}$ Teena Nagar, ${ }^{5}$ Aakash Pandita ${ }^{6}$ \\ 'Department of Medical and Paediatric Oncology, Gujarat \\ Cancer Research Institute, India \\ 2Department of Neonatology, Fernandez hospital, India \\ ${ }^{3}$ All India Institute of Medical Sciences, India \\ ${ }^{4}$ Department of Pediatrics, Umaid Hospital, S.N Medical College, \\ India 5 Hindu Rao Hospital, India
}

\begin{abstract}
Correspondence: Deepak Sharma, Department of Neonatology, Fernandez hospital, Hyderabad, India,, Tel 9849590876, Email dr.deepak.rohtak@gmail.com
\end{abstract}

Received: January 13, 2015 | Published: February 19, 2015
Abbreviations: NCHS, national center for health statistics; SAM, severe acute malnutrition; PEM, protein energy malnutrition; MTC, malnutrition treatment corner

\section{Introduction}

India is home to greatest population of severely malnourished children in the world and accounts for over $20 \%$ of under-five childhood death every year and 2.1 million children in India do not survive to celebrate their fifth birthday. ${ }^{1}$ National family health survey estimates reveal that $45.9 \%$ of India's children under 3 years are underweight, $39 \%$ are stunted and $23 \%$ are wasted and about 8 million (6.4\%) children suffer from acute severe malnutrition and these children have high mortality rate ranging from $20 \%$ to $30 \%{ }^{2}$ Severely malnourished children have a high mortality rate; almost $56 \%$ of childhood death is attributed to malnutrition. Optimal management of these acutely ill children and a good outcome depends on an evidence based regimen of care. Despite concerted efforts in recent years involving policy makers, health care providers and social organisations morbidity and mortality of malnutrition remains a challenge. Severe acute malnutrition (SAM) continues to be an important cause of mortality. In addition to critical care, a nutritional therapy followed by nutritional rehabilitation is a very important aspect for these children. ${ }^{3}$

The present study was, therefore, undertaken to evaluate incidence and clinical profile of patients admitted with severe acute malnutrition and the assessment of relative contribution of various variables.

\section{Methods and material}

This was a prospective study conducted in the malnutrition treatment corner of the Umaid Hospital for women and child health, Dr. S.N. Medical College, Jodhpur for a period January 2010 to December 2010 on patients of severe acute malnutrition admitted in malnutrition treatment corner. Informed consent was obtained from the parents of all children. Institutional ethical committee approval was taken for the study.

Inclusion criteria were (age group 6 month to 5 years):

i. Weight for height/ length -3 SD (WHO/NCHS median height).

ii. Bilateral pedal oedema.

iii. Grossly visible severe wasting. 


\section{Exclusion Criteria}

Children with non-nutritional cause of severe acute malnutrition. Children with severe acute malnutrition those fit in these criteria and admitted in Umaid Hospital will be enrolled in study. Children will be managed in malnutrition treatment corner and these children will be treated by medical and nutritional means as needed. After admission, investigations like Haemoglobin, total and differential leucocytes count, ESR, urine and stool examination, Monteux Test, HIV ELISA , chest X-Ray, electrolytes and other investigations were done as and when required.

A detailed history and physical examination finding will be recorded at the time of admission by using standard methodology and anthropometric measurement expressed in standard deviation from the median of the reference population, this being the commonly use National Centre for Health Statistics (NCHS) standard as recommended for used by the world health organization. Socioeconomic status will be classified according to modified Kuppuswami scale. ${ }^{4}$

\section{Statistical analysis}

The data were entered in Microsoft excel sheet and SPSS software version 16 for windows was used for analysis of results.

\section{Results}

A total of 75 cases were enrolled in the study. Out of all admitted patients, $72(96 \%)$ were below 2 year of age. Male patient constituted $74.6 \%$ of the total with a ratio of $\mathrm{M}: \mathrm{F}=2.9: 1$. The mean age of admitted patients was $14.92 \pm 7.48$ months. Majority of the cases, i.e. $66(88 \%)$ were Hindus and among them $55(83.3 \%)$ were living in rural area. $72(96 \%)$ patients belong to lower socioeconomic scale (III, IV\&V) and only $3(4 \%)$ patients belonged to socioeconomic scale I and II. Most of the caretaker i.e. 67 (89.3\%) were illiterate and father was literate in $49(66.2 \%)$ cases. In all cases, caretakers were mothers. $39(52 \%)$ patients had three or more children in their families including index case. Prevalence of severe malnutrition was more in families having 3 or more children. Majority of patients were either unimmunised or partially immunised i.e. $32(42.7 \%)$ and 33 (44\%) cases respectively. Only $10(13.3 \%)$ patients were immunised as per age.

Out of all admitted patients, 31(41.3\%) had grade IV, followed by $42(32 \%)$ grade III, $16(21.3 \%)$ grade II and $4(5.3 \%)$ grade I malnutrition. Out of 19 female patient, $16(84.2 \%)$ had PEM grade III \& IV while $68.2 \%$ male had PEM grade III \& IV. Out of all severely malnourished patients, $35(46.7 \%)$ had stunting and among them 14 $(40 \%)$ patients were severely stunted. Fever was the most common presenting complaint in $53(70.7 \%)$ patients, followed by vomiting in $39(52 \%)$, loose motion in $35(46.7 \%)$, cough in $35(46.7 \%)$ and loss of appetite or weight loss in $23(30.7 \%)$ patients. Other complaints were oedema in 11(14.7\%), abdominal distension in $5(6.7 \%)$, rash in $3(4 \%)$ and convulsion and ear discharge in $2(2.7 \%)$ patients each (Table 1).

Most common co-morbidity associated with malnutrition were gastrointestinal tract disturbances in $45(60 \%)$, followed by respiratory tract infection in $39(52 \%)$, urinary tract infection in 3 $(4.0 \%)$, otitis media in $2(2.7 \%)$ and septicaemia in $1(1.3 \%)$ patients. Other associated infections were tuberculosis in $7(9.3 \%)$, dysentery in $5(6.7 \%)$, measles in $3(4.0 \%)$, HIV in $3(4.0 \%)$ and malaria in $1(1.3 \%)$ (Table 2). Most common observed vitamin deficiency was vitamin B in $30(40 \%)$, followed by vitamin A in $21(28 \%)$, vitamin D in $5(6.7 \%)$ and vitamin $C$ in $1(1.3 \%)$ patient. Angular stomatitis and conjunctival xerosis were the most common deficiency sign.
Table I Distribution according to Presenting Complaints

\begin{tabular}{lll}
\hline S. No. & Complaints & Number of patient n (\%) \\
\hline I & Fever & $53(70.7)$ \\
2 & Vomiting & $38(50.7)$ \\
3 & Loose motion & $35(46.7)$ \\
4 & Cough & $35(46.7)$ \\
5 & Loss of appetite (Weight loss) & $23(30.7)$ \\
6 & Oedema & II (14.7) \\
7 & Abdominal Distension & $05(6.7)$ \\
8 & Rash & $03(4.0)$ \\
9 & Convulsion & $02(2.7)$ \\
I0 & Bleeding & $02(2.7)$ \\
I I & Ear discharge & $02(2.7)$ \\
\hline
\end{tabular}

Table 2 Distribution according to disease pattern

\begin{tabular}{lll}
\hline S. No. & Morbidity & No. of patient $\mathbf{n}(\%)$ \\
\hline I & Acute diarrhoea vomiting & $28(37.3)$ \\
2 & Bronchopneumonia & $23(30.7)$ \\
3 & Upper respiratory tract infection & $16(2 \mathrm{I} .3)$ \\
4 & Acute vomiting & $10(13.3)$ \\
5 & Tuberculosis & $07(9.3)$ \\
6 & Acute diarrhoea & $07(9.3)$ \\
7 & Dysentery & $05(6.7)$ \\
8 & Measles & $03(4)$ \\
9 & HIV & $03(4)$ \\
I0 & Urinary tract infection & $03(4)$ \\
II & Otitis media & $02(2.7)$ \\
I2 & Septicaemia & $01(1.3)$ \\
I3 & Malaria & $0 \mathrm{I}(\mathrm{I} .3)$ \\
\hline
\end{tabular}

Among all admitted patient with SAM, 64 (85.3\%) patients were anaemic at the time of admission and out of them $38(59.3 \%)$ had moderate, 19 (29.7\%) had severe and 7 (10.9\%) had mild anaemia. $14.7 \%$ patients had normal haemoglobin Level. Out of 75 patients, hypoglycemia was detected in $16(21.3 \%)$ cases having blood sugar less than $54 \mathrm{mg} / \mathrm{dl}$, among them 3 (18.7\%) patient had sugar less than $40 \mathrm{mg} / \mathrm{dl}$. Only $7(9.3 \%)$ patients had exclusive breast feeding up-to 5 months of age. Nearly $74.7 \%$ children were exclusively breast fed up-to two months of age. Only two patients were exclusively breast fed up to 6 months of age. Mean duration of exclusive breast feeding was 2.6 \pm 1.5 months (Table 3).

Table 3 Duration of Exclusive Breast Feeding

\begin{tabular}{lll}
\hline S. No. & Duration (month) & No. of patient n (\%) \\
\hline I & Upto I month & $66(88)$ \\
2 & Upto 2 month & $56(74.7)$ \\
3 & Upto 3 month & $36(48)$ \\
4 & Upto 4 month & $20(26.7)$ \\
5 & Upto 5 month & $7(9.3)$ \\
6 & Upto 6 month & $2(2.7)$ \\
7 & More than 6 month & 0 \\
\hline
\end{tabular}

Weaning had been started in $52(69.3 \%)$ at the time of admission, among them in $13(25 \%)$ weaning was started before 6 months of age, in $18(34.6 \%)$ between 6 to 9 months, in $16(30.8 \%)$ between 9 to 12 months and in $5(9.86 \%)$ patients after 12 months of age. Out of 75 patients, $23(30.7 \%)$ patients with different age groups were yet not started weaning at the time of hospitalisation, among them $10(41.6 \%)$ were between 9 to 12 months of age and $5(20.8 \%)$ were above 12 months of age (Table 4). 
Table 4 Distribution according to Age of Weaning

\begin{tabular}{llll}
\hline S. No. & Age of weaning & $\begin{array}{l}\text { Weaning } \\
\text { started } \mathbf{n}(\%)\end{array}$ & $\begin{array}{l}\text { Semi Solid \& solid food } \\
\text { started } \mathbf{n}(\%)\end{array}$ \\
\hline $\mathrm{I}$ & $<6$ month & $13(25)$ & 0 \\
2 & $6-9$ month & $18(34.6)$ & $11(33.3)$ \\
3 & $9-12$ month & $16(30.7)$ & $10(30)$ \\
4 & $>12$ month & $5(9.6)$ & $12(36.4)$ \\
& Total & 52 & 33 \\
\hline
\end{tabular}

Out of all patients, those started supplementary food, 33 (63.5\%) patients were started semisolid and solid foods along with top milk. Semisolid and solid foods were started between 6 to 9 month in 11 (33.3\%), between 9 to 12 month in $10(30 \%)$ and after 12 month in 12 (36.4\%) patients. Solid or semisolid foods were started after 9 month of age in $22(66.7 \%)$ patients. Mean age of weaning was 8.4 \pm 3.9 months and mean age of starting semisolid to solid food was $11.6 \pm 3.53$ month. Most common used supplementary food was top milk in 52 (100\%), followed by chapati in $22(42.3 \%)$, khichadi /daliya in 17 $(32.7 \%)$ and dal/rice in $10(19.2 \%)$ patients. Most common used top milk was goat milk (61.5\%). Most commonly used weaning method was by katori spoon and cup in $39(75 \%)$ patients, followed by bottle in $9(17.3 \%)$ and both bottle and katori spoon in $4(7.7 \%)$ patients.

Out of 75 patients, $16(21.3 \%)$ were stopped breast feeding at the time of hospitalisation, among them $6(37.5 \%)$ stopped breast feeding before 6 month of age, $1(6.2 \%)$ between 6 to 9 month, $2(12.5 \%)$ between 9 to 12 month and $7(43.7 \%)$ patients after 12 months of age. , $59(78.7 \%)$ patient of different age group were still on breast feed, among them $16(27.1 \%)$ patients were between 6 to 9 month, 19 (32.2\%) between 9 to 12 month and $24(40.67 \%)$ were above 12 month of age. Out of these 59 patients, $36(61 \%)$ patients also received top feed along with breast feed and 23 (39\%) patients were still not started complementary feeding, among them $14(60.8 \%)$ patients were above 9 month of age. $23(30.7 \%)$ patients were on breast feed only and yet not started weaning; among them 9 (39.1\%) patients were below 9 months of age and $14(60.9 \%)$ patients were above 9 months of age (Table 5). Severity of malnutrition (III \& IV) was more in patients of above 9 months of age as compared to those below 9 months of age $(78.5 \% \mathrm{v} / \mathrm{s} 55.5 \%)$.

Table 5 Degree of malnutrition in patients those still on breasts feed only

\begin{tabular}{|c|c|c|c|c|c|c|}
\hline \multirow{2}{*}{ S. No. } & \multirow{2}{*}{ Age group } & \multirow{2}{*}{ No. of patients } & \multicolumn{4}{|c|}{ Degree of malnutrition $\mathbf{n}(\%)$} \\
\hline & & & & II & III & IV \\
\hline I & $\leq 9$ month & 9 & $I(I I . I)$ & $3(22.2)$ & $4(44.4)$ & $\mathrm{I}(\mathrm{II} . \mathrm{I})$ \\
\hline \multirow[t]{2}{*}{2} & $>9$ month & 14 & $\mathrm{I}(7.1)$ & $2(14.4)$ & $5(35.7)$ & $6(42.8)$ \\
\hline & Total & 23 & 2 & 5 & 9 & 7 \\
\hline
\end{tabular}

\section{Discussion}

Protein energy malnutrition (PEM) predominantly seen between infancy and childhood i.e. from 6 months to 5 years of age. Severe malnutrition is not only an important cause of morbidity and mortality, but also leads to permanent impairment of physical and possibly mental growth of those who survive. In addition to critical care, a nutritional therapy followed by nutritional rehabilitation is a very important aspect for these children. Thus, present study was conducted in malnutrition treatment corner (MTC) of Umaid hospital for women and children health Dr. S.N. medical college, Jodhpur to find out the incidence, clinical profile of severe acute malnutrition.

In this study, incidence of severe acute malnutrition was $3.28 \%$. According to recent national family health survey prevalence of severe acute malnutrition is $6.4 \%{ }^{2}$. This high prevalence was due to lack of awareness about malnutrition in community especially in rural population due to high illiteracy level of mothers and lower socioeconomic status of family. Since NFHS is community based while our study was hospital based and in India parents generally do not seek medical advice for these malnourished children until unless they suffer from some of the acute complications of SAM e.g. diarrhoea, vomiting, bronchopneumonia, fever, convulsion, skin infection etc.

Out of total 75 patients enrolled in the study, 96\% patients were below 24 months of age. The mean age of admitted patients was $14.92 \pm 7.48$ months. Sharma ${ }^{5}$ in their study also reported that prevalence of malnutrition is significantly high in children less than 24 months of age. Similarly, Mamidi et al., ${ }^{6}$ in their study on hospital based treatment of severe malnutrition reported that $71.1 \%$ of children were below 24 months of age. In initial 2 to 3 year of life rapid growth occurs and requirement of substrates for energy and building of tissue also increases, thus deficiency of protein, energy and other micronutrients in these year results in malnutrition.

In the enrolled subjects of our study, males were more than females $(74.6 \% \mathrm{v} / \mathrm{s} 25.4 \%)$ with a ratio of $2.9: 1$. Similar to our study, Ashraf et al., ${ }^{7}$ reported that malnutrition is relatively more common in males as compared to that of females (53.7\% v/s 46.3\%). Likewise, Aneja et al., ${ }^{8}$ in their study on malnutrition observed that $55.5 \%$ of children were males as compared to females (44.5\%). But Joshi et al., ${ }^{9}$ observed that incidence of malnutrition was higher in females $(78 \%)$ as compared to that in males (22\%). Singh et al., ${ }^{10}$ and Rao et al., ${ }^{11}$ reported that extent of malnutrition was significantly higher in girls than boys i.e. $(\mathrm{p}<0.05)$ and $(\mathrm{p}<0.01)$ respectively. This difference may be due to the fact that Joshi et al., ${ }^{9}$ Singh et al., ${ }^{10}$ and Rao et al., ${ }^{11}$ did field studies in general population where malnutrition is more common in female counterpart as compared to male whereas Ashraf et al., ${ }^{7}$ Aneja et al., ${ }^{8}$ and present studies were hospital based where male patients were more than female which might be due to the fact that male children are bought to hospital early and are given more importance. Moreover male child gets more medical attention than female and in rural area parents usually does not seek medical advice for female child. Ritual and social norms are also responsible for it.

In the index study, majority of the cases $(88 \%)$ were Hindus and malnutrition was more $(82.7 \%)$ in rural area. This represents the prevalence of these two communities in local population. Similarly, Malik et al., ${ }^{12}$ reported that malnutrition was more in Hindus as compared to Muslims (70.7\% v/s 29.2\%) but the severity of malnutrition (PEM grade III and IV) was more in Muslims which may be due to the fact that Muslims has large family size, low literacy level and belonged to low socioeconomic status. Singh et al., ${ }^{10}$ and Rao et al., ${ }^{11}$ also observed the same. Ashraf et al. ${ }^{7}$ in their study revealed that malnutrition was more prevalent $(\mathrm{p}<0.01)$ in children living in nonindustrial than industrial area $(82.8 \% \mathrm{v} / \mathrm{s} 17.1 \%)$. Poor nutritional status of rural children compared to their urban counterparts is due to the cumulative effect of a series of less favourable conditions, including lower socioeconomic conditions, improper maternal prenatal and birthing care, poor quality of complementary feeding and poor immunization status.

We observed that in the enrolled patients, $96 \%$ patients belonged to lower socioeconomic status (Kuppuswami scale III, IV \& V). ${ }^{4}$ Severe malnutrition was infrequent in upper socioeconomic class. Soni et al., ${ }^{13}$ and Ashraf et al., ${ }^{7}$ in their studies reported that majority of malnourished children belonged to lower socioeconomic status (IV and V) i.e. $72.8 \%$ and $90 \%$ respectively. Likewise, Rao et al., ${ }^{11}$ Singh et al., ${ }^{10}$ and Swaminathan et al., ${ }^{14}$ also reported that malnutrition 
is related to per capita income and socioeconomic condition. A study by Wagstaff and Watanabe ${ }^{15}$ found inverse relation between underweight and socioeconomic inequality. These results indicate that unavailability of food, poor purchasing power, inappropriate distribution and inadequate utilization might make the children vulnerable to malnutrition in a deprived community.

We observed that $89.3 \%$ caretakers were illiterate and in almost all cases mothers were the caretaker. Fathers were literate in $66.2 \%$ cases. Similar to our study, Joshi et al., ${ }^{9}$ observed that malnutrition was more $(64 \%)$ in children whose mothers were educated up-to primary level as compared to those educated up-to secondary or higher level (31\%). Likewise, Mittal et al., ${ }^{16}$ reported that prevalence is the highest where mothers are illiterate $(60.9 \%)$ compared to $21.2 \%$ where mothers were educated more than high school. Sharma ${ }^{5}$ in his study also reported that most of the children belong to low income group respectively and prevalence of PEM was more $(70 \%)$ in children whose mothers were illiterate. High prevalence of under nutrition of both kinds among under-fives highly suggests that there is a strong need for educating the mothers about timely weaning and weaning foods which are easily available at home as well as in local market, that too at low cost. The number of malnourished children decreased as the literacy status of mothers improved because better education makes the mother aware of the importance of immunisation, breast feeding, family planning and birth spacing, hygiene and a balance diet.

In the enrolled patient, prevalence of severe malnutrition was higher $(52 \%)$ in the family having 3 or more children. Rao et al., ${ }^{11}$ in their study on malnutrition in urban slums reported that average family size was 5.77 . Likewise, Sharma. ${ }^{5}$ also reported that prevalence of malnutrition significantly higher in families having more than 2-3 sibling. It might be due to relatively low per capita income and poor childcare practices. Most of the children in our study were either unimmunised $(42.7 \%)$ or partially immunised $(44 \%)$. Sharma, Shah ${ }^{17}$ and Devdas et al., ${ }^{18}$ observed that better the socioeconomic and educational status of mothers; better was the immunisation status of children. It is due to the fact that most of the children in our study belonged to rural area and their mother's literacy and socioeconomic status was also low. A substantial proportion of rural parents are unaware of the protective value of immunisation.

The results of the present study showed that $41.3 \%, 32.1 \%, 21.3 \%$ and $5.3 \%$ patients were in PEM grade IV, III, II and I respectively. Female patients were more severely malnourished than males $(84.2 \%$ $\mathrm{v} / \mathrm{s} 68.21 \%$ ). Females are more likely to be malnourished than males and severity of malnutrition is also more in female children. Similar to our study, Mittal et al., ${ }^{16}$ observed that more males (35.29\%) were affected with lower grades of PEM (grade I and II) than females $(32.85 \%)$, whereas severe grades of PEM (grade III and IV) were common in females $(5.71 \%)$ than in males $(2.94 \%)$.

Out of all severely malnourished patients, $46.7 \%$ had stunting; of which $40 \%$ were severely stunted. Mittal et al., ${ }^{16}$ also reported that $38.38 \%$ had low weight for age whereas $46.06 \%$ had low height for age. The most common presenting symptom in the present study were fever $(70.7 \%)$, followed by vomiting $(52 \%)$, loose motion $(46.7 \%)$ cough $(46.7 \%)$ and loss of appetite or weight loss (30.7\%).Other common presenting symptom were oedema $(14.7 \%)$, abdominal distension (6.7\%) and ear discharge (2.7\%). Bernal et al., ${ }^{19}$ and Bagga et al. ${ }^{20}$ in their study also reported diarrhoea and fever as common presenting symptom. Ashraf et al., ${ }^{7}$ also reported that diarrhoea $(25.8 \%)$ and fever/vomiting $(30.9 \%)$ were the common presenting symptom in malnourished children.
Most common co morbidity associated with PEM was gastrointestinal $(60 \%)$ followed by respiratory tract infection $(52 \%)$, UTI (4\%) and otitis media (2.7\%). Other associated co-infection were tuberculosis $(9.3 \%)$, dysentery $(6.7 \%)$, measles $(4 \%)$, HIV $(4 \%)$ and malaria $(1.3 \%)$, Sharma et al. ${ }^{5}$ reported in his study that the incidence of malnutrition interlinked with infections was $4 \%$. Diarrhoea and dysentery constitute majority of infections (about 50\%) and second most common infection was recurrent upper and lower respiratory infection. Bernal et al. ${ }^{19}$ reported that most common associated illness at admission was diarrhoea (68.4\%), among these $31.5 \%$ were dehydrated. Diarrhoea and dysentery constitute majority of infection $(50 \%)$ and second most common infection was respiratory tract infection. Vijakaram and Bhaskaran ${ }^{21}$ in their study found a significant association between PEM and Tuberculosis. Thrustans et al. ${ }^{22}$ reported that overall prevalence of HIV in severely malnourished patients is $21.6 \%$. Malnutrition adversely affects the immune status of children and makes them more vulnerable to infections. In severely malnourished patients, both acquired immunity i.e. lymphocyte functions as well as innate host defence mechanisms i.e., macrophages and granulocytes are affected. Diminished immune functions render undernourished patients more susceptible to infections.

We found out that, Vitamin B deficiency was most common (40\%) followed by Vitamin A (28\%), Vitamin D (6.7\%) and Vitamin C (1.3\%) and most common deficiency sign were cheliosis, angular stomatitis and conjunctival xerosis . Chainani et al. ${ }^{23}$ in their study compared different vitamin deficiency between malnourished and normally nourished children and observed prevalence of vitamin A deficiency in $(15.7 \% \mathrm{v} / \mathrm{s} 1.8 \%)$, vitamin B in $(7.6 \% \mathrm{v} / \mathrm{s} 0.4 \%)$, vitamin D in $(11.9 \%$ $\mathrm{v} / \mathrm{s} 2 \%)$ and vitamin $\mathrm{C}$ in $\left(1.1 \% \mathrm{v} / \mathrm{s}\right.$ o \%) children. Sharma et al., ${ }^{24}$ also reported vitamin A deficiency in $8.7 \%$ and vitamin B in $32.5 \%$ of malnourished patients. Mathur et al., ${ }^{25}$ Singh et al., ${ }^{26}$ Choudhary et al. ${ }^{27}$ and Chandna and Sehgal ${ }^{28}$ also reported that angular stomatitis, xerosis of conjunctiva, cheliosis and glossitis were the most common vitamin deficiency sign. The different vitamins deficiency seen in SAM patients is because of lack of adequate nutritious food intake and the food which is taken have very low amount of vitamins and minerals making them deficient in the required vitamins.

In the present study, $85.3 \%$ patients were anaemic at the time of admission and out of them $10.9 \%$ had mild, 59.3\% had moderate and $29.7 \%$ had severe anaemia. Soni et al., ${ }^{13}$ in their study reported that incidence of anaemia was $60 \%$ in malnourished children and among them majority (69.2\%) of children had haemoglobin level between 5 $\mathrm{gm} / \mathrm{d}$ to $7 \mathrm{gm} / \mathrm{dl}$. Anaemia in PEM has been attributed to a number of factors including nutritional deficiencies, infections, blood loss, haemolysis, and erythroid hypoplasia, ineffective erythropoiesis due to vitamin B12 and folic acid deficiency and adaptation to lower metabolic oxygen requirements.

There is general agreement that fasting blood glucose is lower in malnourished children then in recovered or normal children, though there is wide variation in the blood glucose levels in various studies. In the index study apart from anaemia, hypoglycaemia was detected in $21.3 \%$ cases having blood sugar less than $54 \mathrm{mg} / \mathrm{dl}$. Mild to moderate hypoglycaemia is quite common in cases of PEM which has no risk of mortality but symptomatic profound hypoglycaemia is life threatening and requires urgent treatment. Symptomatic hypoglycaemia is more common in marasmus where energy stores are depleted.

Breast milk is the best available food for infant and those who have been deprived of this, are expected to show a greater prevalence of malnutrition. We observed that only $9.3 \%$ patients had exclusive breast feeding up-to 5 month of age. Nearly $74.7 \%$ children were 
exclusively breast fed up-to two months of age. Mean duration of exclusive breast feeding was $2.6 \pm 1.5$ months. Likewise, Aneja et al., ${ }^{8}$ reported in their study that among 155 children (6-12 months of age), nearly, $41 \%$ were exclusively breastfed for less than two months and only $20 \%$ were exclusively breastfed till the age of 5-6 months. The mean weight of children who were exclusively breastfed for two months was $4.5 \pm 3.9 \mathrm{~kg}$ as compared to $6.0 \pm 4.5 \mathrm{~kg}$ for those who were exclusively breastfed for 6 months. Similarly, Mallik et al., ${ }^{12}$ also reported that among the children less than two years, malnutrition was observed significantly more in those who were not exclusively breast fed than the children exclusively breast fed for 4- 6 months. This could be explained as breast milk is a complete source of all vitamins, proteins, fat and carbohydrate for the growing child and also decreases chances of infections in exclusively breast feed infants in the initial six month of age.

Out of 75 patients enrolled in the study, 21.3\% children stopped breast feeding at the time of hospitalisation, among them $37.5 \%$ stopped before 6 months of age and another $43.7 \%$ were breast fed beyond 12 month of age. $78.7 \%$ children were still on breast feed at the time of hospitalisation and among them $40.7 \%$ of children were above 12 months of age. Singh et al., ${ }^{10}$ conducted a study on infant feeding and weaning practices in the rural communities in Rajasthan and observed that only $23 \%$ of mothers initiated breast feeding within 24 hours of delivery and most mothers breast feed for at least 2 years. Similarly, Rasania and Sachdev ${ }^{29}$ conducted a study to assess the nutritional status and breast feeding practices among children and observed that, the duration of breast feeding was found to be significantly associated with malnutrition $(p<0.05)$. Duration of breast feeding showed indirect relation to the nutritional status, longer the duration of breast feeding beyond the age of 6 months, higher the prevalence and severity of malnutrition. Different studies found increase in mild to severe malnutrition in children who were breast fed during second year of life. Prolonged breast feeding may reduce the consumption of complementary foods without an equivalent increase in human milk intake, thereby, diminishing total energy intake. Hossain et al. ${ }^{30}$ and Nube and Assenso-Okyere, ${ }^{31}$ while assessing the effect of prolonged breast feeding on the nutritional status, observed considerably lower nutritional status of children who continue to receive the breast milk up-to 2 nd and 3 rd year of life in comparison with fully weaned children in the same year.

Out of 75 patients of the present study, $30.7 \%$ patients were on breast feed only and yet not started weaning and among them $60.9 \%$ patients were above 9 months of age. Severity of malnutrition (PEM grade III \& IV) was more $(78.5 \%)$ in those patients who were on breast feed only above 9 months of age compared to those below 9 months of age (55.5\%). Similarly, Nube and Assenso-Okyere ${ }^{31}$ also observed that higher prevalence of malnutrition is associated with prolonged breast fed children because weaning is delayed or supplementary feeding is not given to these children at appropriate time. This association of severe degree of malnutrition with prolonged breast-feeding is also in agreement with the findings of Jahan and Hassan $^{32}$ and Hossain et al. ${ }^{33}$ This study observations strengthen the view that breast feeding should be supplemented with complementary feeding after six month of age as nutrition and calorie requirements in these infants increases after six month which cannot be completed by exclusive breast feeding.

We observed in the present studythat $69.3 \%$ patients had started weaning at the time of hospitalization and among them $25 \%$ started before 6 months of age and another $40.7 \%$ after 9 months of age. Amongst these patients, $63.5 \%$ started semisolid to solid food along with top milk. It was observed that only $33.3 \%$ children were consuming semisolid to solid foods at 6 to 9 months of age and rest of patients started weaning after 9 months of age. $30.6 \%$ patients did not start weaning at the time of admission and among them $65.2 \%$ were above 9 months of age. Mean age of weaning was $8.4+3.9$ months and mean age of starting semisolid and solid food was $11.6+3.53$ months. Rasania and Sachdev ${ }^{29}$ in their study reported that weaning was started at optimum age (4-6month) in $42.9 \%$ children, started early ( $<4$ month) in $24.5 \%$ and in rest it was delayed beyond 6 months of age. Severe malnutrition was significantly higher $(\mathrm{p}<0.05)$ in children where weaning was delayed. Likewise, Aneja et al., ${ }^{8}$ in their study on urban slums children (age 6 to 12 months), observed that $82.0 \%$ children received top milk and among them about $68 \%$ children started receiving it when they were less than 6 months of age. It was also observed that only $47 \%$ children were consuming semisolids at 6 to 7 months of age. Similarly, Singh et al., ${ }^{10}$ also reported that only $24.7 \%$ of mothers introduced supplementary foods before 6 months of age and mean age of food supplementation initiation was 8.7 months. Delayed weaning is also detrimental to health. Prevalence of malnutrition was more in children where breast-feeding was continued for longer period, because as the age advances, breast milk remains inadequate for the children.

Apart from age of weaning, type of supplementary food and method of feeding are also important. In our study, we observed that $69.3 \%$ patients received top milk supplementation and most commonly used top milk was goat milk. The most common supplementary semisolid food given was Chapatti followed by Khichari. Common mode of feeding top milk was katori spoon $(75 \%)$ followed by bottle $(17.3 \%)$ and both katori spoon and bottle (7.7\%). Aneja et al., ${ }^{8}$ also reported that most common mode of feeding top milk was katori spoon (67.7\%) followed by bottle $(28.3 \%)$ and most common complimentary semisolid food was khichadi followed by rice. Rasania and Sachdev ${ }^{29}$ also observed in their study that $65.8 \%$ of mothers were using bottle for feeding top milk and overall malnutrition prevalence was higher $(\mathrm{p}<0.001)$ in bottle fed children $(83 \%)$ and most common supplementary foods were milk, rabadi, rice, and roti. Inspite of heavy efforts to stop bottle feeding in children, it is still prevalent to a large extent in community, so much so up-to $25 \%$. This shows that more intensive measure have to be taken to eradicate it from community. Bottle fed children are more prone to get infection due to poor hygienic conditions of both bottle and nipple.The bottle feeding should not be encouraged in the society as this is very detrimental for infant health and makes the infant prone to various infections like diarrhoea and starts the vicious circle of PEM.

\section{Conclusion}

On the basis of this study, we conclude that the problem of severe malnutrition is multi-dimensional and inter-generational in nature. Prevalence of severe acute malnutrition is still high in community $(6.4 \%)$ as well as in hospital setting (3.28\%). The determinants of severe malnutrition includes household food insecurity, illiteracy, low socioeconomic status, lack of awareness to access health services, large family size and poor purchasing power etc. Besides these, faulty feeding practices, poor complementary feeding practices, ignorance about nutritional needs of infants and young children and repeated infections, also aggravates the malnutrition amongst children. So there is strong need to educate the parents, especially mothers about nutritive diets that they can prepare at home with available means or can be purchased from market at low cost . Apart from nutritional education, importance of breast feeding, time of weaning, birth spacing, family planning, immunisation and literacy, have to be realised to the parents. It is very important to communicate to the 
policy planners the urgency to address the problem of severe acute malnutrition. The policy planners should concentrate on adequate nutrition of the girl child because the malnourished mother give rise to malnourished and small for gestational age newborn and also this leads to early weaning from breast feeding and hence this vicious cycle of PEM continuous in the society. The other thing which should be focused is the proper follow up of these malnourished children and to see the adequate growth of these children's. The parents of these children's need to bre sensitized about the problem of their child and explained about the care needed. As the problem of PEM is seen mainly in low status population, hence they must be educated about the low cost and nutritious food.

\section{Authorship contribution ship}

RPN, MC, DS: Substantial contributions to the conception or design of the work and the acquisition, analysis, or interpretation of data for the work.

TN, AP, BDG, AP: Drafting the work or revising it critically for important intellectual content.

RPN, MC, DS, TN,AP, BDG, AP: Final approval of the version to be published.

RPN, MC, DS, TN, AP, BDG, AP: Agreement to be accountable for all aspects of the work in ensuring that questions related to the accuracy or integrity of any part of the work are appropriately investigated and resolved.

\section{Acknowledgments}

None.

\section{Conflicts of interest}

None.

\section{Funding}

None.

\section{References}

1. The state of the world's children. Child survival in Geneva- UNICEF flagship report. UNICEF Geneva, Switzerland. 2008.

2. International Institute for Population Sciences (IIPS) and Macro International. National Family Health Survey (NFHS-3), 2005-06, Volume 2, Mumbai: IIPS, India. 2007. p.1-168.

3. Caulfield LE, de Onis M, Blossner M, et al. Under nutrition as an underlying cause of child death associated with diarrhoea, pneumonia and measles. Am J Clin Nutr. 2004;80(1):193-198.

4. Mishra D, Singh HP. Kuppuswamy's socioeconomic status scale: A revision. Indian J Pediatr. 2003;70(3):273-274.

5. Sharma LM. P1190 A study of malnutrition and associated infection in children in urban private Hospital in India. Journal of Pediatric Gastroenterology \& Nutrition. 2004;39(1):S509.

6. Mamidi RS, Kulkarni B, Radhakrishana KV, et al. Hospital based nutrition rehabilitation of severely undernourished children using energy dense local foods. Indian Pediatr. 2010;47(8):687-693

7. Ashraf S, Javed MT, Abbas N, et al. Malnutrition in diseased children with reference to age, sex, socio-economic status and area of living. Int J Agri Biol. 2001;3(4):419-422.

8. Aneja B, Singh P, Tandon M, et al. Etiological factors of malnutrition among infants in two urban slums of Delhi. Indian Pediatr. 2001;38(2):160-165.
9. Joshi S, Walgankar SS. Epidemiology of malnutrition in a rural field practice area of navi Mumbai. Indian J Prev Soc Med. 2004;35(1\&2):80-84.

10. Singh MB, Fotedar R, Laxminarayan J, et al. Studies on nutritional status of children aged 0-5 years in a drought affected desert area of western Rajasthan, India. Public Health Nutr. 2006; 9(8):961-967.

11. Rao S, Joshi SB, Kelkar RS. Change in nutritional status and morbidity over time among preschool children from slums in Pune India. Indian Pediatr. 2000;37(10):1060-1671.

12. Mallik S, Mitra SP, Basu SS, et al. Malnutrition: A missed opportunity to treat at tertiary care. Indian Journal of Community Medicine. 2006;31(3):196-197.

13. Soni AL, Singh RN, Gupta BD. Nutritional disorders in rural Rajasthan. Indian J Pediat. 1980;47(3):199-202

14. Swaminathan MC, Jyothi KK, Singh R, et al. A semi longitudinal study of growth of Indian children and the related factors. Indian Pediatr. $1964 ; 1: 255-263$

15. Wagstaff A, Watanabe N. Socioeconomic inequality in child malnutrition in developing world. World Bank, Policy research working paper. $2000 ; 2434$.

16. Mittal A, Singh J, Ahluwalia SK. Effect of maternal factors on nutritional status of 1-5 year old children in urban slum population. Indian $J$ Community Med. 2007;32(4):264-267.

17. Shah PM. Report of nutrition subcommittee of the Indian Academy of pediatrics. Indian Pediatrics. 1972;9(6):360.

18. Devadas RP, Rajlakshmi R, Kaveri R. Influence of family income and parent's education on the nutritional status of preschool children. Indian Journal of Nutrition and Dietetics. 1980;17(7):237-244

19. Bernal C, Velasquez C, Alcaraz G, et al. Treatment of severe malnutrition in children: Experience in implementing the WHO Guidelines in Turbo, Colombia. J Pediatr Gastroentol Nutr. 2008;46(3):322-328.

20. Bagga A, Tripathi $P$, Jatana $V$, et al. Bacteriuria and urinary tract infection in malnourished children. Pediatr Nephrol. 2003;18(4):366-370.

21. Vijakaram M, Bhaskaran. National institutional nutritional, Indian council of medicine research centre, Jamia Usmania, Hyderabad. Nutritional Health Science. 1990;462:1106.

22. Thurstans S, Kerac M, Maleta K, et al. HIV prevalence in severely malnourished children admitted to nutrition rehabilitation units in Malawi: Geographical \& seasonal variations a cross-sectional study. BMC Pediatrics. 2008;8:22.

23. Chainani N, Sharma P, Meena N, et al. Pattern of vitamin deficiencies among the malnourished preschool children in ICDS blocks of Jaipur city. Indian J Matern Child Health. 1994;5(4):109-111.

24. Sharma B, Mitra M, Chakrabarty S, et al. Nutritional status of preschool children of Raj Gond-a tribal population in Madhya Pradesh, India. Mal J Nutr. 2006;12(2):147-155.

25. Mathur JS, Mehrotra SK, Maheshwari BB. Nutritional disorders among children below five years in a rural community. The Indian Journal of Pediatrics. 1974;41(5):184-191.

26. Singh MB, Haldiya KR, Laxminarayan J. Morbidity pattern and its association with malnutrition in preschool children in desert area of Rajasthan, India. Journal of Arid Environments. 2002; 51(3):461-468.

27. Choudhary KK, Hanif MA, Rasheed S, et al. Gender inequality and severe malnutrition among children in a remote rural area of Bangladesh. J Health Popul Nutr. 2000;18(3):123-130.

28. Chandna S, Sehgal S. Prevalence of deficiency diseases among schoo aged children. Health arid Population Perspectives and Issues. 1994;17(1\&2):108-113. 
29. Rasania SK, Sachdev TR. Nutritional status and feeding practices of children attending MCH centre. Indian Journal of Community Medicine. 2001;26(3):07-09.

30. Hossain MM, Hassan MQ, Rahman MH, et al. Hospital management of severely malnourished children: comparison of locally adapted protocol with WHO protocol 2007. Indian Pediatr. 2009;46:213-217.

31. Nube M, Assenso-Okyere WK. Large differences in nutritional status between fully weaned and partially breast-fed children beyond the age of 12 months. Eur J Clin Nutr. 1996;50(3):171-177.
32. Jahan K, Hassan H. Nutritional status of children and relationship with some characteristic of mother and children. Bangladesh J Nutr. 1994;7:1-8.

33. Hossain MI, Yasmin R, Kabir I. Nutritional and immunization status, weaning practices and socio-economic conditions of under five children in three villages of Bangladesh. Indian $J$ Public Health. 1999;43(1):37-41. 